\title{
Heterogeneous sea-level rises along coastal zones and small islands
}

Article

Accepted Version

Creative Commons: Attribution-Noncommercial-No Derivative Works 4.0

Li, G., Li, X., Yao, T., Che, T., Yang, H., Ma, M., Zhao, H. and Pan, X. (2019) Heterogeneous sea-level rises along coastal zones and small islands. Science Bulletin, 64 (11). pp. 748755. ISSN 2095-9273 doi: https://doi.org/10.1016/j.scib.2019.04.023 Available at https://centaur.reading.ac.uk/84288/

It is advisable to refer to the publisher's version if you intend to cite from the work. See Guidance on citing.

To link to this article DOI: http://dx.doi.org/10.1016/j.scib.2019.04.023

Publisher: Elsevier

All outputs in CentAUR are protected by Intellectual Property Rights law, including copyright law. Copyright and IPR is retained by the creators or other copyright holders. Terms and conditions for use of this material are defined in the End User Agreement.

\section{www.reading.ac.uk/centaur}

\section{CentAUR}

Central Archive at the University of Reading 
Reading's research outputs online 


\section{Heterogeneous sea-level rises along coastal zones and small islands}

Guoshuai Li ${ }^{\text {abc }}$ Xin $\mathrm{Li}^{\mathrm{ab}}$ Tandong $\mathrm{Yao}^{\mathrm{ab}}$ Tao Che ${ }^{\mathrm{bc}}$ Hong Yang ${ }^{\mathrm{d}}$ Mingguo Ma ${ }^{\mathrm{e}}$ Haipeng Zhao ${ }^{\mathrm{f}}$ Xiaoduo Pan ${ }^{\mathrm{a}}$

${ }^{a}$ Institute of Tibetan Plateau Research, Chinese Academy of Sciences, Beijing 100101, China

${ }^{\mathrm{b}}$ Center for Excellence in Tibetan Plateau Earth Sciences, Chinese Academy of Sciences, Beijing 100101, China

${ }^{\mathrm{c}}$ Northwest Institute of Eco-Environment and Resources, Chinese Academy of Sciences, Lanzhou 730000, China

${ }^{\mathrm{d}}$ Department of Geography and Environmental Science, University of Reading, Whiteknights, Reading RG6 6AB, UK

${ }^{\mathrm{e}}$ Research Base of Karst Eco-environments at Nanchuan in Chongqing, Ministry of Natural Resources, School of Geographical Sciences, Southwest University, Chongqing 400715, China

${ }^{\mathrm{f}}$ Department of Earth and Environmental Systems, Indiana State University, Terre Haute, IN 47809, USA

\section{Abstract}

Coastal zones and many small islands are highly susceptible to sea-level rise (SLR). Coastal zones have a large exposed population and integrated high-value assets, and islands provide diverse ecosystem services to millions of people worldwide. The coastal zones and small islands affected by SLR are likely to suffer from submergence, flooding and erosion in the future. However, very few studies have addressed the heterogeneity in SLR changes and the potential risk to coastal zones and small islands. Here we used the mean sea level (MSL) derived from satellitealtimetry data to analyse the trends and accelerations of SLRs along global coastal zones and small islands. We found that except for the Antarctic coastal zone, the annual MSL within $50 \mathrm{~km}$ of the coasts presented an increasing trend of $3.09 \pm 0.13 \mathrm{~mm}$ $\mathrm{a}^{-1}$ but a decreasing acceleration of $-0.02 \pm 0.02 \mathrm{~mm} \mathrm{a}^{-2}$ from 1993 to 2017. The highest coastal MSL trend of $3.85 \pm 0.60 \mathrm{~mm} \mathrm{a}^{-1}$ appeared in Oceania, and the lowest trend of $2.32 \pm 0.37 \mathrm{~mm} \mathrm{a}^{-1}$ occured in North America. Africa, North America and South America showed acceleration trends, and Eurasia, Australia and Oceania had deceleration trends. Further, MSLs around global small islands reflected an increasing trend with a rate of $3.01 \pm 0.16 \mathrm{~mm} \mathrm{a}^{-1}$ but a negative acceleration of $-0.02 \pm 0.02 \mathrm{~mm} \mathrm{a}^{-2}$. Regional heterogeneity in the trends and accelerations of MSLs along the coasts and small islands suggests that stakeholders should take discriminating precautions to cope with future disadvantageous impacts of the SLR. 


\section{Introduction}

Assessment of the impacts of sea-level rise (SLR) on highly vulnerable areas such as coastal zones and many small islands is very important [1]. The population in the low-elevation coastal zones was 625.2 million people in 2000 worldwide and will probably increase to 948.9 million by 2030 and $1,388.2$ million by 2060 [2]. With millions of islands worldwide, including an estimated 17,883 with an area $>1 \mathrm{~km}^{2}[3]$, the rapidly increasing populations of island inhabitants will continue to exert considerable stress on freshwater, land and other resources [4]. In addition to a large exposed population, coastal zones and small islands have valuable infrastructures and substantial national wealthy [5] that are highly susceptible to severer storm surges [6]. Furthermore, some islands are included on the World Heritage list [7] as curcial heritage sites [5].

Satellite altimetry data can be used to address the deficiencies in spatial and temporal measurements by tide gauges for assessing SLR. Satellite altimetry data can operationally monitor adverse impacts along coastal zones and small islands. SLR is one of the largest climate-change-driven factors that affect the habitability of coastal zones and small islands [1], [8], [9] and may cause submergence, flooding, erosion [10], and shoreline changes [11] as well as saltwater intrusion to groundwater of coastal zones and small islands [12], [13]. Mean sea level (MSL) is often used to measure SLR. The global ocean MSL accelerated at a rate of $0.018 \pm 0.007 \mathrm{~mm} \mathrm{a}^{-2}$ from 1902 to 1990 according to the average tide gauge record[14], and global warming-induced global ocean MSL acceleration increased to $0.084 \pm 0.025 \mathrm{~mm} \mathrm{a}^{-2}$ after corrections for the eruption of Mount Pinatubo [15] and El Niño-Southern Oscillation (ENSO) effects from 1993 to 2017 based on precise satellite altimetry data [16].

The global ocean MSL increased at a rate of $3.34 \mathrm{~mm} \mathrm{a}^{-1}$ from 1993 to 2018 based on near real-time satellite altimetry data [17]. MSL is a measure of the sea level variations over time and presents the mean change in the sea-level anomaly (SLA) located in assigned longitude-latitude grids. The effects of SLR on small islands have been widely reported [18], [19], [20], [21]. Indisputably, heterogeneous assessments of SLR changes need to consider the MSL, which includes the climate-change-driven global MSL [16] and local variations caused by the melting of glaciers, ice-caps, and mountain glaciers; ocean circulation patterns; ocean heat content [22], [23], [24]; interannual or decadal variability; glacial isostatic adjustment; and tectonic movement [25]. Although extreme sea levels [26] often occurred in association with severe weather events or tsunamis, MSL based on several million individual point measures of SLA is still a better general sign of the effects of SLR on coastal zones and small islands. Currently, insufficiently detailed algorithms confine to large footprints of satellite altimetry data [27] and the signal discernment between land and water and/or wet tropospheric correction remains unsolved issues. However, we can still use the MSL distributed within a certain grid range to approximately assess the effect of SLR on coastal zones and small islands. To the best of our knowledge, the MSL changes along coastal zones and small islands using 25year time series of precise satellite altimetry data have rarely been investigated. Thus, we investigated herein the following two questions: what were the MSL changes along coastal zones and small islands? How strong was the MSL heterogeneity in these vulnerable areas? Potential MSL heterogeneity could impact a large exposed population and lead to the shifting of high-value assets. The examination of MSLs in these vulnerable areas is important for effective adaptation and mitigation of SLR. 
Here we present the first risk mapping of the heterogeneous distribution of the MSL changes along coastal zones including coastal subzones, and small islands from 1993 to 2017. We considered the annual-scale MSL variations within $50 \mathrm{~km}$ adjacent to coastal zones and small islands based on a global climatology grid product $\left(0.25^{\circ}\right)$. Small islands from each ocean region always share approximately common characteristics [28], and here we do not consider the potential effects of the numbers of islands in different ocean region. The MSL changes along small islands were examined strictly following the boundary partition of ocean regions, thus, some islands were divided into several different ocean regions. Risk mapping of the MSL heterogeneity could indicate various responses in different locations and focus the attention of policy makers on the more susceptible places. The quantification of the MSL trend and acceleration along coastal zones including coastal subzones, and small islands can help coastal countries and small island developing states form adaptation polices and management plans to mitigate the hazards brought by the SLR.

\section{Materials and methods}

\subsection{Study area}

The study area includes coastal zones and small islands between $69^{\circ} \mathrm{S}$ and $83^{\circ} \mathrm{N}$. Due to the large variation in Antarctica ice-sheet shorelines, MSL changes in this regionwas excluded. The world vector shoreline used the full-resolution shapefiles from the Global Self-consistent Hierarchical Highresolution Geography (GSHHG) Version 2.3.7, June 15, 2017 [29]. The corresponding continental GSHHG shorelines were masked and revised based on the world continents produced by the ESRI, Global Mapping International, U.S. Central Intelligence Agency (The World Factbook) (https://www.arcgis.com/home/item.html?id=a3cb207855b348a297ab85261743351d)

. The corresponding continents are Asia, Africa, Europe, Australia, North America, South America and Oceania after excluding Antarctica. Small islands examined in this study were derived by the International Hydrographic Organization (IHO) ocean regions (http://www.marineregions.org/about.php) [30] (Fig. S1 online). Coastal subzones were defined by combining continents and contiguous ocean regions (Table S1online). Overall, 134 coastal subzones (Table S1 online) and 100 ocean regions (Table $\mathrm{S} 2$ online) are included in the current study.

\subsection{MSL processing}

Global or regional MSL was directly computed on a mean grid of SLAs from an equiarea average box $\left(0.25^{\circ} \times 0.25^{\circ}\right)$ to allow each cycle to distribute the measurements equally by weighting each box according to its longitude-latitude and its areal coverage of the surface of the ocean. The annual MSL was averaged from the monthly mean SLA product with a resolution of $0.25^{\circ}$.

The SLA is defined as the sea surface height minus the mean sea surface and minus known geophysical corrections. The SLA data were extracted from the Ssalto/Ducas altimeter product produced and distributed by the Copernicus Marine and Environment Monitoring Service (CMEMS) (http://www.marine.copernicus.eu). Maps of Sea Level Anomalies-Height (MSLA-H) global delay-time monthly mean product data [31] were obtained from the Archiving, Validation and Interpretation of Satellite Oceanographic (AVISO) website (ftp://ftpaccess.aviso.altimetry.fr/climatology/global/delayed-time/monthly_mean/).

The SLA is defined as [32] 
SLA $=$ Orbit $-($ Range + Dry troposphere + Wet troposphere + Ionosphere $)-$

Ocean tide-Solid earth tide - Pole tide - Sea state bias - Combined atmospheric correction - Mean sea surface, where Orbit is the altitude of the satellite above the reference ellipsoid; Range is the altimeter range including all instrumental corrections; Dry troposphere is the altimeter range correction due to the dry troposphere field; Wet troposphere is the altimeter range correction due to the wet troposphere field; Ionosphere is the altimeter range correction due to the ionosphere field; Ocean tideis the geocentric ocean tide (sum of the sea surface height amplitude due to the geocentric ocean tide and the load tide height for the geocentric ocean tide); Solid earth tide is the sea surface height amplitude due to the earth tide; Pole tide is the sea surface height amplitude due to the pole tide field; Sea state bias is the sea surface height bias due to the sea surface roughness field; Combined atmospheric correction is the sea surface height correction due to air pressure and high-frequency winds; and Mean sea surface is the mean sea surface height above the reference ellipsoid.

\subsection{Calculation of trend and acceleration}

The annual MSL grids were transformed into point measurements located in the grid centres, and a buffer of $50 \mathrm{~km}$ along the vector shorelines of the coastal zones and ocean region islands was used to mask these point measurements. All the annual means of point measurements were integrated to calculate the annual mean of coastal zone and ocean region island MSLs. The MSL trend was deduced from this time series using a least squares linear method [33]. The uncertainties are given as 1 standard error (s.e.) of the estimates of the slope value [34]. A least squares quadratic fitting was performed to calculate the acceleration, where the acceleration is twice the quadratic coefficient [15], [16] and the uncertainty is 1 s.e., defined by the standard deviation of the sample and the sum of the weights in the calculation of the quadratic coefficient [34]. The time period is from 1993 to 2017.

\section{Results}

\subsection{MSL trend on coastal zones}

The annual global coastal MSL increased at a rate of $3.09 \pm 0.013 \mathrm{~mm} \mathrm{a}^{-1}$ from 1993 to 2017 (Fig. 1a). Combined with a $5^{\circ}$ grid distribution, this increase meaned that large parts of coastal zones in Southeast Asia, Oceania and Northern Australia and a small portion of Northern Eurasia, especially in Sweden and Finland around the Baltic Sea, had greater SLRs. For example, more than $6.0 \mathrm{~mm} \mathrm{a}^{-1}$ of increased MSL trends occurred in some locations, suggesting that these zones were suffering more from severer SLR threats. Western coastal zones in Canada and the United States, located on the North America continent, presented lower and nonsignificant trends in coastal MSL. The MSL trends of most grids around South America coastal zones were no more than $4.0 \mathrm{~mm} \mathrm{a}^{-1}$. Some grids around the Svalbard archipelago and western Greenland coastal zones had negative trends of less than $-1.0 \mathrm{~mm} \mathrm{a}^{-1}$, and their standard errors seemed to be slightly exaggerated but not significant. These exaggerated standard errors of certain grids may be related to nonuniform ice-thinning rate and ice-coverage extension, especially in the Svalbard archipelago [35]. The exaggerated standard errors in northern Eurasia may be related to the Arctic seaice loss [36] (Fig. 1a). 


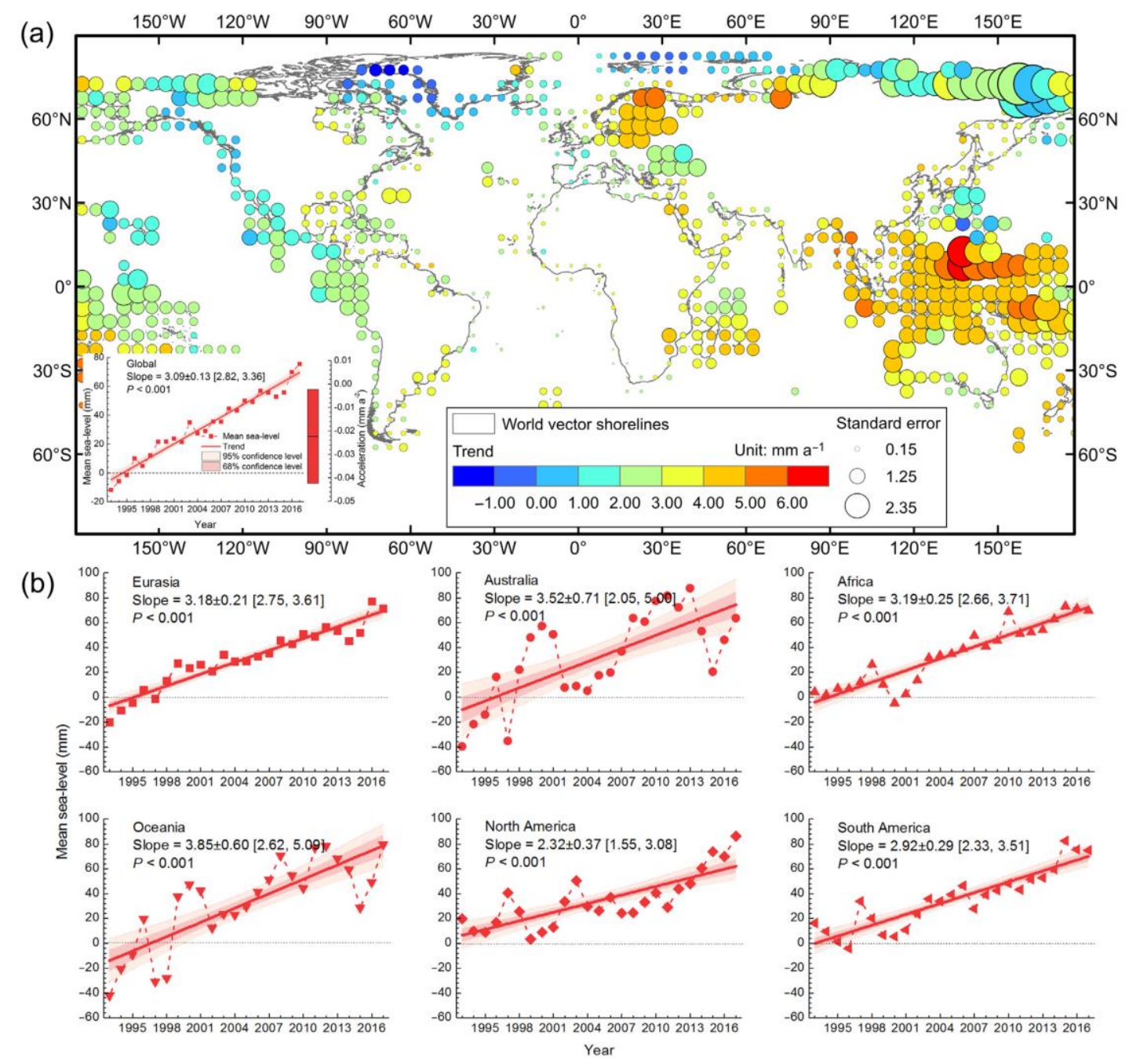

Fig. 1. Heterogenous distribution of global coastal MSL trends from 1993 to 2017. (a) Data were shown on a $5^{\circ} \times 5^{\circ}$ grid and superimposed on world vector shorelines. Coastal MSLs were extracted after a buffering of $50 \mathrm{~km}$ based on world vector shorelines. The linear trends of integrating the annual mean of individual coastal MSL grids $\left(0.25^{\circ}\right)$ into defined grids $\left(5^{\circ}\right)$ were calculated, with the blue representing decreases and the red representing increases. The uncertainty is 1 standard error (s.e.). The red squares represented the annual MSLs. The trend was fitted through the red fitting line, with the $68 \%$ and $95 \%$ confidence levels (shaded medium red and light red, respectively) representing the statistical errors of the annual trend's fitting. The slope is the linear trend estimate (unit, $\mathrm{mm} \mathrm{a}^{-1}$ ) [33], showing the slope \pm 1 s.e. of the linear trend. The left and right values in the square bracket are the lower bound (95\%) and upper bound (95\%) of the trend, respectively. The $P$, the trend's significance, was determined using a linear trend test. The grey dotted line represented the zero-equivalent MSL line. The inset boxplot represented global acceleration with acceleration \pm 1 s.e. derived by the quadratic fitting of the annual global coastal MSL from 1993 to 2017. (b) The same as the inset of Fig. 1a but for individual continents.

Coastal MSL trends showed great heterogeneity, with the difference between Oceania and North America as high as $1.53 \mathrm{~mm} \mathrm{a}^{-1}$ (Fig. 1b). At the continental scale, the annual coastal MSLs of North America and South America had lower significant 
trends of $2.32 \pm 0.37$ and $2.92 \pm 0.29 \mathrm{~mm} \mathrm{a}^{-1}$, respectively, which were less than those of the other continents (Fig. 1b).

Of all 134 coastal subzones, the highest MSL trend appeared in Arctic Ocean North America $\left(5.93 \pm 1.40 \mathrm{~mm} \mathrm{a}^{-1}\right)$, and the lowest MSL trend was negative in Baffin Bay North America ( $\left.-0.61 \pm 0.65 \mathrm{~mm} \mathrm{a}^{-1}\right)$ from 1993 to 2017. In the 14 coastal subzones of Africa, Gulf of Aqaba Africa had the highest MSL trend $\left(4.29 \pm 0.72 \mathrm{~mm} \mathrm{a}^{-1}\right)$ and Alboran Sea Africa had the lowest MSL trend $\left(2.18 \pm 0.45 \mathrm{~mm} \mathrm{a}^{-1}\right)$. Australia was surrounded by 8 coastal subzones, ranging between 2.68 and $4.70 \mathrm{~mm} \mathrm{a}^{-1}$. The MSL trends in the 75 coastal subzones fell in the range of 0.34 and $5.01 \mathrm{~mm} \mathrm{a}^{-1}$, corresponding to Arctic Ocean Eurasia and Arafura Sea Eurasia. Baffin Bay North America and Davis Strait North America in North America coastal subzones did not manifest significant MSL trends from 1993 to 2017. In Oceania, the severest coastal subzone was Solomon Sea Oceania, with an MSL increasing trend of $5.07 \pm 1.26 \mathrm{~mm}$ $\mathrm{a}^{-1}$. The lowest MSL trend in South America coastal subzones was observed in Southern Ocean South America $\left(1.60 \pm 0.39 \mathrm{~mm} \mathrm{a}^{-1}\right)$ (Table S1 online).

\subsection{MSL trend around small islands}

The slope of global island MSL in the 100 ocean regions showed an increasing trend of $3.01 \pm 0.16 \mathrm{~mm} \mathrm{a}^{-1}$ (Fig. 2b). Island MSL trends displayed a wider range of $5.85 \mathrm{~mm} \mathrm{a}^{-1}$, from $-0.78 \pm 0.68 \mathrm{~mm} \mathrm{a}^{-1}$ in Baffin Bay to $5.07 \pm 1.26 \mathrm{~mm} \mathrm{a}^{-1}$ in Solomon Sea (Fig. 2a and Table S2 online). Except for Baffin Bay, other island MSL trends were positive (Table S2 online). Of the island MSL trends of typical ocean regions, the Pacific Ocean, including the North Pacific Ocean and South Pacific Ocean, had the highest trend of $3.19 \pm 0.22 \mathrm{~mm} \mathrm{a}^{-1}$; the Atlantic Ocean, including the North Atlantic Ocean and South Atlantic Ocean, had the second highest trend of $2.76 \pm 0.16 \mathrm{~mm} \mathrm{a}^{-1}$; and the Mediterranean Sea, including the Mediterranean SeaEastern Basin and Mediterranean Sea-Western Basin, had the third highest trend of $2.65 \pm 0.32 \mathrm{~mm} \mathrm{a}^{-1}$ (Fig. 2b). 


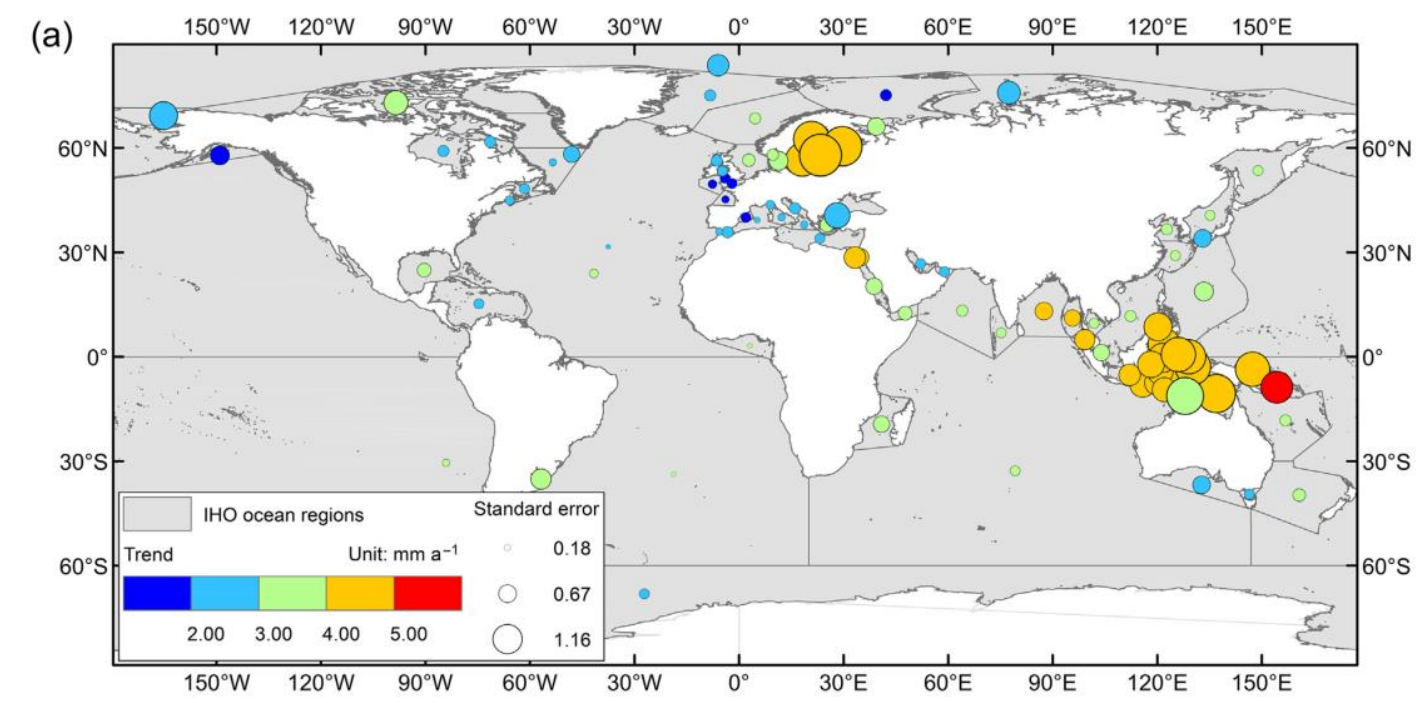

(b)

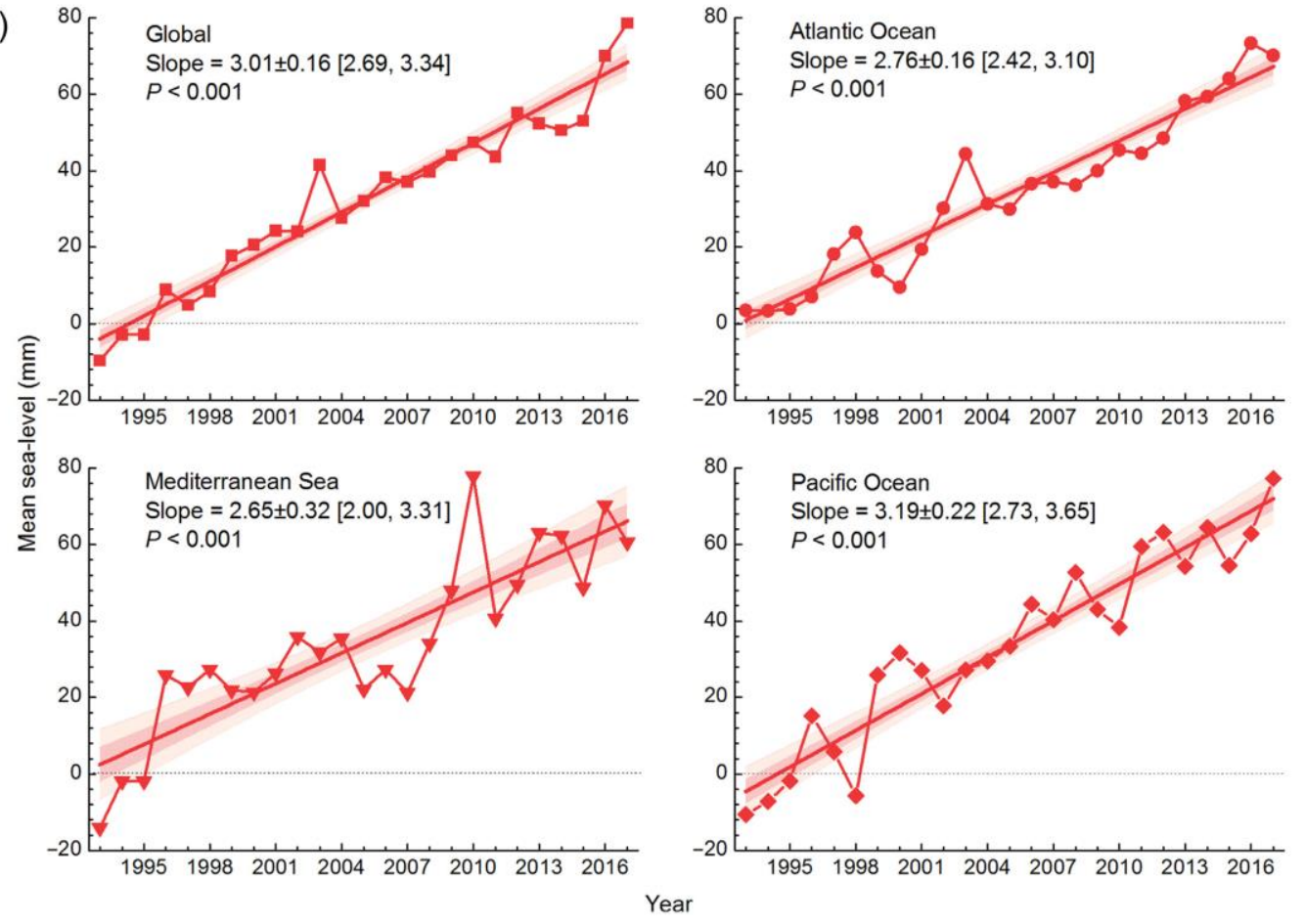

Fig. 2. Heterogenous distribution of global island MSL trends from 1993 to 2017. (a) The International Hydrographic Organization (IHO) ocean regions are superimposed on the full-resolution shapefiles from GSHHG [29]. The grid cell size is $30^{\circ} \times 30^{\circ}$. Blueindicates decreasing trends, while red indicates increasing trends. Errors are given in terms of the s.e. The nonsignificant island MSL trends of the Laptev Sea, East Siberian Sea, Baffin Bay, Sea of Azov, Davis Strait, the Coastal Waters of Southeast Alaska and British Columbia, Beaufort Sea, Black Sea and Gulf of California were not labeled. For more details about names and trends, see Fig. S1 and Table S2 (Online). (b) The same as Fig. 1b but for the typical ocean regions. The typical ocean regions include the Atlantic Ocean (sum of North Atlantic Ocean and South Atlantic Ocean), Mediterranean Sea(sum of Mediterranean Sea-Eastern Basin and Mediterranean Sea-Western Basin) and Pacific Ocean (sum of North Pacific Ocean and South Pacific Ocean).

From the heterogenous distribution of island MSL trends, most ocean regions showed significant increasing trend; 9 of 100 ocean regions indicated poor capture of the MSLs and nonsignificant changes $(P>0.05)$. The largest of the 100 ocean regions 
examined here $\left(75.39 \times 10^{6} \mathrm{~km}^{2}\right)$ is the South Pacific Ocean, where the island MSL trend was $3.21 \pm 0.32 \mathrm{~mm} \mathrm{a}^{-1}$. The Strait of Gibraltar, which is the smallest ocean region $\left(1.66 \times 10^{3} \mathrm{~km}^{2}\right)$, displayed a trend of $2.25 \pm 0.32 \mathrm{~mm} \mathrm{a}^{-1}$ from 1993 to 2017 (Fig. 2a and Table S2 online). In other words, $91 \%$ of ocean regions displayed significant increasing island MSL trends from 1993 to 2017 (Fig. 2a and Table S2online), likely affected by SLR.

\subsection{MSL acceleration on coastal zones}

The annual global coastal MSL had a negative acceleration of $-0.02 \pm 0.02 \mathrm{~mm}$ $\mathrm{a}^{-2}$ from 1993 to 2017 (Fig. 1a); the determinate coefficient was 0.963, indicating that this result was credible to some degree. Heterogeneous distribution of global coastal MSL accelerations was also calculated (Fig. 3). Although the MSL trend of most grids in North America and South America were no more than $4.0 \mathrm{~mm} \mathrm{a}^{-1}$ (Fig. 1a), their accelerations were largely higher than $0.2 \mathrm{~mm} \mathrm{a}^{-2}$. Southeast Asia, Oceania and Northern Australia had negative accelerations, the MSL accelerations of certain grids were less than $-0.6 \mathrm{~mm} \mathrm{a}^{-2}$. However, in Sweden and Finland, their accelerations were greater than zero, with possible consequence of more severer MSL trends (Fig. 3). In short, the Eastern Hemisphere inclined to negative accelerations of MSL and Western Hemisphere inclined to positive accelerations of MSL at the continental scale. Note that the heterogeneous distribution of global coastal accelerations in Fig. 3 corresponded to the heterogeneous distribution of global coastal trends in Fig. 1a.

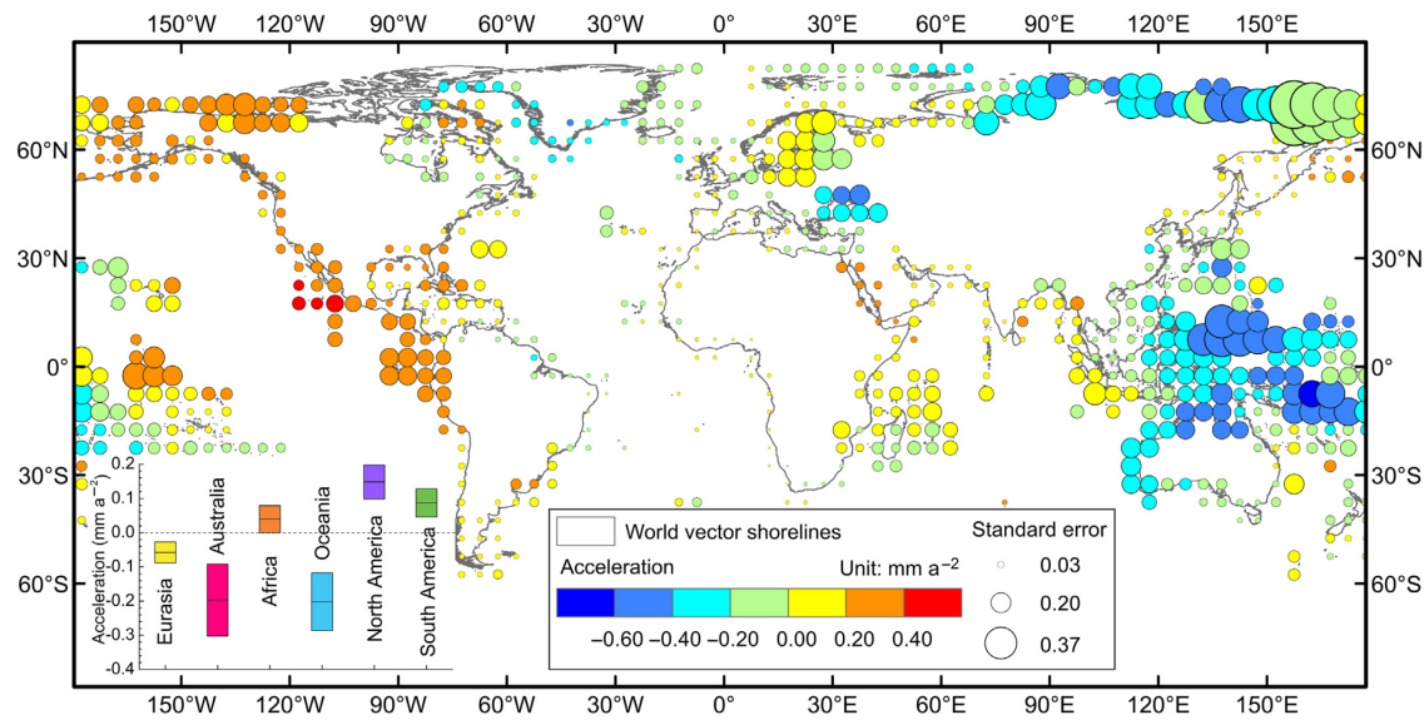

Fig. 3. Heterogeneous distribution of global coastal MSL accelerations from 1993 to 2017. Data were shown on a $5^{\circ} \times 5^{\circ}$ grid and superimposed on world vector shorelines. Coastal MSLs were extracted after a buffering of $50 \mathrm{~km}$. The quadratic accelerations of the annual coastal MSL grids $\left(0.25^{\circ}\right)$ in the respective grids $\left(5^{\circ}\right)$ were calculated, with the blue representing decreases and the red representing increases. The uncertainty is 1 s.e. The different color boxplots represented coastal accelerations among individual continents, with the acceleration \pm 1 s.e. The acceleration was derived by quadratic fitting of the annual MSLs in Fig. $1 b$.

With respect to the $-0.02 \pm 0.02 \mathrm{~mm} \mathrm{a}^{-2}$ of global coastal MSL acceleration (Fig. 1a), Eurasia, Australia and Oceania had more negative accelerations of $-0.06 \pm 0.03$, $-0.20 \pm 0.11$ and $-0.20 \pm 0.08 \mathrm{~mm} \mathrm{a}^{-2}$, respectively. Africa, South America and North America had more positive accelerations of $0.04 \pm 0.04,0.09 \pm 0.04$ and $0.15 \pm 0.05 \mathrm{~mm} \mathrm{a}^{-2}$, respectively (Fig. 3). 
Sixty-four of 134 coastal subzones had positive accelerations higher or equal to $0.01 \mathrm{~mm} \mathrm{a}^{-2}$, and 64 coastal subzones had negative accelerations lower or equal to $-0.01 \mathrm{~mm} \mathrm{a}^{-2}$. The other 8 coastal subzones had no evident accelerations, ranging between -0.01 and $0.01 \mathrm{~mm} \mathrm{a}^{-2}$. The MSL accelerations of all the 134 coastal subzones ranged between $-0.53 \mathrm{~mm} \mathrm{a}^{-2}$ in Timor Sea Australia and $0.50 \mathrm{~mm} \mathrm{a}^{-2}$ in Arctic Ocean North America. Of 8 coastal subzones in Australia, only South Pacific Ocean Australia had a positive acceleration $\left(0.10 \pm 0.11 \mathrm{~mm} \mathrm{a}^{-2}\right)$. Additionally, only North Atlantic Ocean South America had a negative acceleration $(-0.13 \pm 0.05 \mathrm{~mm}$ $\mathrm{a}^{-2}$ ) among South America coastal subzones. Negative accelerations were all observed in the 10 Oceania coastal subzones (Table S1 online).

\subsection{MSL acceleration around small islands}

As with global coastal MSL acceleration, global island MSL also had a negative acceleration of $-0.02 \pm 0.02 \mathrm{~mm} \mathrm{a}^{-2}$ but an increasing trend of $3.01 \pm 0.16 \mathrm{~mm} \mathrm{a}^{-1}$, indicating that the global island MSL trend decelerated from 1993 to 2017. In the typical ocean regions, island MSL acceleration in the Atlantic Ocean was positive at $0.03 \pm 0.03 \mathrm{~mm} \mathrm{a}^{-2}$, whereas that in the Mediterranean Sea was negative at $-0.03 \pm 0.05 \mathrm{~mm} \mathrm{a}^{-2}$, and the island MSL acceleration in the Pacific Ocean was $-0.04 \pm 0.03 \mathrm{~mm} \mathrm{a}^{-2}$ (Fig. 4).

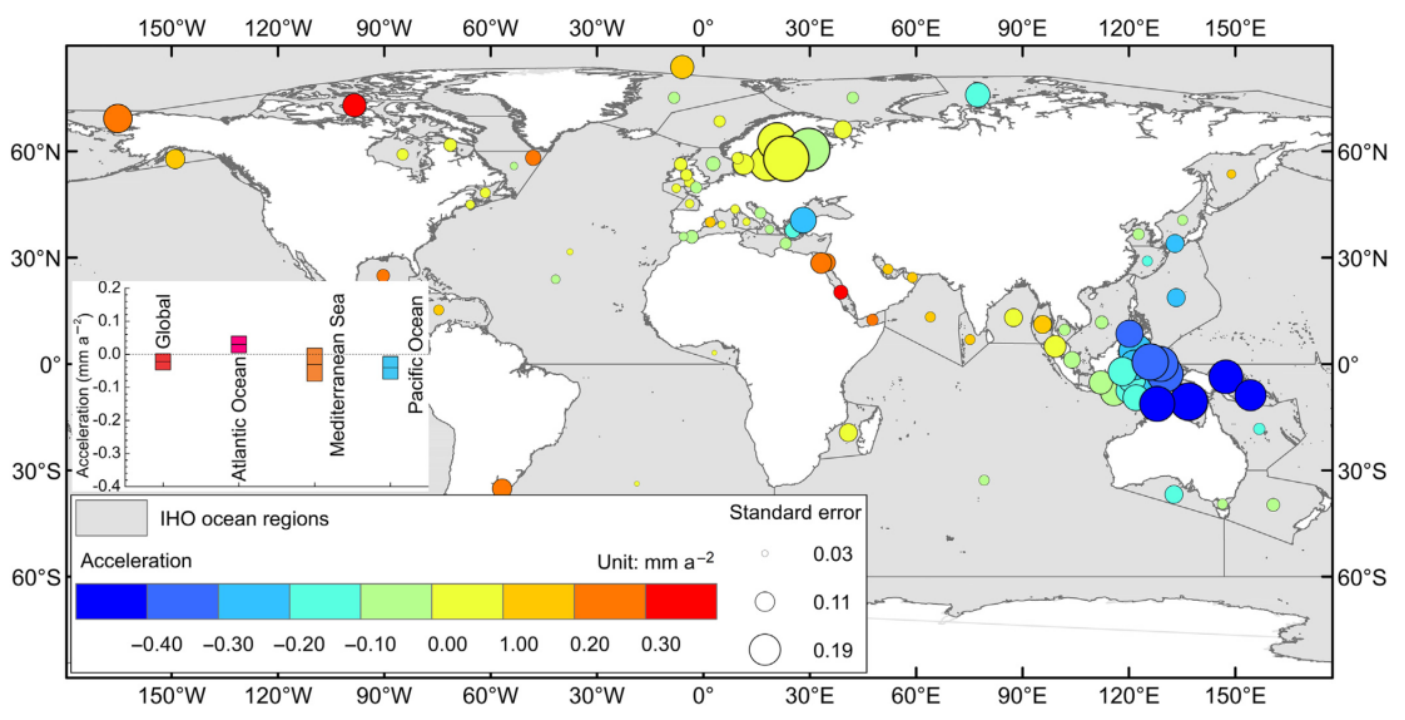

Fig. 4. Heterogeneous distribution of global island MSL accelerations from 1993 to 2017. The same as Fig. 2a but for island MSL accelerations. Island MSL accelerations corresponding to nonsignificant island MSL trends in certain ocean regions were not labeled. The typical ocean regions were the same as those in Fig. $2 b$. The different colorboxplots represented global and typical ocean region accelerations, with acceleration \pm 1 s.e. The accelerations were derived by quadratic fitting of annual MSLs for global and typical ocean regions.

According to heterogenous distribution and statistics of island MSL accelerations, with the exception that the island MSL trend in Baffin Bay was negative at $-0.78 \pm 0.68 \mathrm{~mm}$ $\mathrm{a}^{-1}(P>0.1)$, the other 50 ocean regions had decelerating but increasing trends. The English Channel, North Sea, Hudson Bay, Irish Sea and St. George's Channel and Inner Seas off the West Coast of Scotland had zero accelerations but significant increasing trends. Forty-four ocean regions had accelerating and increasing trends (Table S2 online and Fig. 4a). Island MSL accelerations ranged from $-0.49 \pm 0.20 \mathrm{~mm} \mathrm{a}^{-2}$ in Timor Sea to $0.36 \pm 0.13 \mathrm{~mm} \mathrm{a}^{-2}$ in Gulf of California. The South Pacific Ocean, the largest of 100 ocean regions, had an 
acceleration of $-0.05 \pm 0.05 \mathrm{~mm} \mathrm{a}^{-2}$, and the Strait of Gibraltar, the smallest ocean region, had an acceleration of $-0.01 \pm 0.05 \mathrm{~mm} \mathrm{a}^{-2}$ (Table S2 online). Similarly, island MSL accelerations in the different ocean regions displayed different responses that correspond to the threats imposed by SLR in different ocean regions.

\section{Discussion and conclusion}

Finer-scale evaluation of the heterogeneous distribution of MSL trends and accelerations along coastal zones and small islands is useful for better understanding how coastal zones and small islands should adapt to global warming-induced SLR. We found that the decreasing order of coastal MSL trends among continents was Oceania, Australia, Africa, Eurasia, South America and North America. A total of 128 of 134 coastal subzones contiguous the world continents, excluding Antarctic, exhibited increasing MSL trends from 1993 to 2017. Positive accelerations were most common in Western Hemisphere coastal subzones, and negative acceleration were most common in Eastern Hemisphere coastal subzones (Fig. S1 and Table S1 online), roughly corresponding to the heterogeneous distribution of global island MSL accelerations in Fig. 4. Of all 100 ocean regions, global island MSL trend and acceleration roughly fell in the range of the distribution of global coastal MSL trend and acceleration, respectively. In total, coastal zones and small islands had shown increasing MSL trends from 1993 to 2017.

The global ocean MSL acceleration $\left(0.01 \pm 0.01 \mathrm{~mm} \mathrm{a}^{-2}\right)$ from 1993 to 2017 in this study (Table S2 online) was approximate to the acceleration recorded by tide gauges $\left(0.018 \pm 0.007 \mathrm{~mm} \mathrm{a}^{-2}\right)$ [14] but lower than the corrected climate-change-driven global ocean MSL acceleration $\left(0.084 \pm 0.025 \mathrm{~mm} \mathrm{a}^{-2}\right)$ from the Jason series satellitealtimetry data for the same study period [16], which may be related to non-climate-change-driven factors. The global coastal MSL acceleration $\left(-0.02 \pm 0.02 \mathrm{~mm} \mathrm{a}^{-2}\right)$ (Fig. 1a) was approximate to the global ocean MSL deceleration of $-0.02 \pm 0.02 \mathrm{~mm} \mathrm{a}^{-2}$ caused by the eruption of Mount Pinatubo in 1991 [15]; thus, the deceleration in global coastal MSL may be related to a slow recovery of sea level that was decreased by the eruption of Mount Pinatubo in 1991 [16]. The global ocean MSL trend $\left(2.88 \pm 0.08 \mathrm{~mm} \mathrm{a}^{-1}\right)$ from 1993 to 2017 in this study was lower than that from 1993 to $2009\left(3.4 \pm 0.4 \mathrm{~mm} \mathrm{a}^{-1}\right)$ [37], and the global island MSL trend $\left(3.01 \pm 0.16 \mathrm{~mm} \mathrm{a}^{-1}\right)$ from 1993 to 2017 in this study accorded with the not yet fully understood errors (2-4 mm) [38], compared with the $3.31 \mathrm{~mm} \mathrm{a}^{-1}$ increasing global ocean MSL trend from 1993 to 2017 following the AVSIO+ [17]. This underestimate was likely related to the method used to process monthly averaged MSLA, corresponding to the weekly maps of delayed-time SLAs averaged month by month from January 1993 and averaged again year by year. Averaging over monthly or annual scales may counteract extremely high SLAs in some grids, which may have resulted in an underestimate in this study.

The heterogeneous distribution of coastal MSL trends may be directly related to different mean significant wave heights [39] caused by wind along world vector shorelines, although gravity waves may flatten wave height changes over two or three months. Additionally, changes in the land terrestrial water storage (TWS) [40], even in the world endorheic basins [9], may indirectly contribute to coastal MSL change. Changes in TWS along word vector shorelines have increasing (decreasing) trends and recharge (discharge) water into the land [41], roughly corresponding to the heterogeneous distribution of global coastal MSL accelerations. In particular, for ice-sheet loss, glacier and ice-cap loss, $\sim 32 \%$ of glacier area and $\sim 21 \%$ of glacier volume [42] are located in the Eastern Hemisphere, which may limit the increase in coastal MSL accelerations; thus, Eurasia, Australia and Oceania had decelerating trends. With $\sim 52 \%$ of glacier area and $\sim 56 \%$ of glacier volume [42] located in the Western Hemisphere, mass loss contribution may result in positive MSL accelerations in Africa, North America and South America. Changes from coastal winds and land TWS, especially ice-sheet loss, glacier and ice-cap loss and sea-iceloss [36], may result in the complexity of spatial uncertainties of the pattern. 
In the current study, the MSL was successfully used to estimate SLR in coastal zones and small islands. Differences in MSLs had been found in these vulnerable areas. When planning and developing coastal zones and small islands, we should consider characterizing their bioclimatic and physical characterization [3] to develop alternative options for adaptation to rising sea-levels [43]. Some hot-spot areas, such as crucial World Heritage sites [5] and migratory bird stopover habitats [44], walls, flood-resistant aluminum barriers and elevated embankments could be constructed along coastal zones and small islands. In fact, ensuring the continued habitability of small islands in different ocean regions cannot be separated from the attempt to achieve emission reductions and energy savings on the national and international levels.

The initial quantification of risk mapping of the MSL heterogeneity along coastal zones and small islands focusing on the trends and accelerations can inform local governments regarding how the MSL might change in the future and help them to adopt targeted and purposeful measures to minimize the adverse impacts. In total, the SLR heterogeneity strongly suggested that Oceania had faced the most severe but decelerating SLRs, while North America ranked the last, and world islands faced an increased severity of SLR during the period of 1993-2017.

\section{Conflict of interest}

The authors declare that they have no conflict of interest.

\section{Acknowledgments}

This work was supported jointly by the Strategic Priority Research Program of Chinese Academy of Sciences (XDA20100104 and XDA20100300), and the 13th Five-year Informatization Plan of Chinese Academy of Sciences (XXH13505-06). We thank Ying Zhang, Yanzhao Zhou and Hanqing Ma for helping with data processing.

\section{Author contributions}

X. Li and T. Yao conceived the idea; G. Li, X. Li, H. Yang and T. Yao led the writing of the manuscript; T. Che and M. Ma participated in discussions; and H. Zhao and X. Pan assisted with the analysis of the data.

\section{References}

[1] R.J. Nicholls, A. Cazenave Sea-level rise and its impact on coastal zones

Science, 328 (2010), pp. 1517-1520

[2] B. Neumann, A.T. Vafeidis, J. Zimmermann, et al.Future coastal population growth and exposure to sea-level rise and coastal flooding - a global assessment

PLoS One, 10 (2015), p. e0118571

[3] P. Weigelt, W. Jetz, H. KreftBioclimatic and physical characterization of the world's islands Proc Natl Acad Sci USA, 110 (2013), pp. 15307-15312

[4] K.B. Karnauskas, J.P. Donnelly, K.J. AnchukaitisFuture freshwater stress for island populations Nat Clim Change, 6 (2016), pp. 720-725

[5] L. Reimann, A.T. Vafeidis, S. Brown, et al.Mediterranean UNESCO world heritage at risk from coastal flooding and erosion due to sea-level rise Nat Commun, 9 (2018), p. 4161

[6] N. Lin, K. Emanuel, M. Oppenheimer, et al.Physically based assessment of hurricane surge threat under climate change Nat Clim Change, 2 (2012), pp. 462-467

[7] UNESCO. World heritage list. 2018, (April 18, 2018): http://whc.unesco.org/en/list/. 
[8] M. Schuerch, T. Spencer, S. Temmerman, et al.Future response of global coastal wetlands to sea-level rise Nature, 561 (2018), pp. 231-234

[9] J. Wang, C. Song, J.T. Reager, et al.Recent global decline in endorheic basin water storages Nat Geosci, 11 (2018), pp. 926-932

[10] Church JA, Clark PU, Cazenave A, et al., Sea level change, In: Stocker TF, Qin D, and Plattner GK, (Eds.), Climate Change 2013: The Physical Science Basis Contribution of Working Group I to the Fifth Assessment Report of the Intergovernmental Panel on Climate Change, 2013, Cambridge University Press, Cambridge, United Kingdom and New York, NY, USA, 1137-1216.

[11] N. Xu, P. GongSignificant coastline changes in China during 1991-2015 tracked by Landsat data Sci Bull, 63 (2018), pp. 883-886

[12] M.E. Gonneea, A.E. Mulligan, M.A. CharettClimate-driven sea level anomalies modulate coastal groundwater dynamics and discharge Geophys Res Lett, 40 (2013), pp. 2701-2706

[13] S.S. Kaushal, G.E. Likens, M.L. Pace, et al.Freshwater salinization syndrome on a continental scale Proc Natl Acad Sci USA, 115 (2018), pp. E574-E583

[14] S. Dangendorf, M. Marcos, G. Wöppelmann, et al.Reassessment of 20th century global mean sea level rise Proc Natl Acad Sci USA, 114 (2017), pp. 5946-5951

[15] J.T. Fasullo, R.S. Nerem, B. HamlingtonIs the detection of accelerated sea level rise imminent? Sci Rep, 6 (2016), p. 31245

[16] R.S. Nerem, B.D. Beckley, J.T. Fasullo, et al.Climate-change-driven accelerated sealevel rise detected in the altimeter era Proc Natl Acad Sci USA, 115 (2018), pp. 2022-2025

[17] AVISO+. Mean sea level product and image interactive selection. 2018, (January 28th, 2019): https://www.aviso.altimetry.fr/en/data/products/ocean-indicators-products/mean-sealevel/products-images.html.

[18] A.D. Henry, A.E. Christensen, R. Hofmann, et al.Influence of sea level rise on discounting, resource use and migration in small-island communities: an agent-based modelling approach Environ Conserv, 44 (2017), pp. 381-388

[19] J.D. Gulley, A.S. Mayer, J.B. Martin, et al.Sea level rise and inundation of island interiors: assessing impacts of lake formation and evaporation on water resources in arid climates Geophys Res Lett, 43 (2016), pp. 9712-9719

[20] M. Becker, B. Meyssignac, C. Letetrel, et al.Sea level variations at tropical Pacific Islands since 1950 Glob Planet Change, 80-81 (2012), pp. 85-98

[21] P.L. Woodworth, D.T. Pugh, R.M. BingleyLong-term and recent changes in sea level in the Falkland Islands J Geophys Res Oceans, 115 (2010), p. C09025

[22] A. Cazenave, W. LlovelContemporary sea level rise Annu Rev Mar Sci, 2 (2010), pp. $145-173$

[23] S.Y. Tony, C. FrankDeep ocean warming assessed from altimeters, gravity recovery and climate experiment, in situ measurements, and a non-boussinesq ocean general circulation model J Geophys Res Oceans, 116 (2011), pp. 1-16

[24] Y.J. Li, Y.S. XuThe study of ocean warming trend based on sea level change in 20022014 Oceanol Limnol Sin, 48 (2017), pp. 712-720

[25] T.F. Stocker, D. Qin, G.K. Plattner, et al.IPCC, 2013: Climate Change 2013: the Physical Science Basis. Contribution of Working Group I to the Fifth Assessment Report of the Intergovernmental Panel on Climate Change Cambridge University Press, Cambridge, United Kingdom and New York, NY, USA (2013), p. 1535 
[26] T. Wahl, I.D. Haigh, R.J. Nicholls, et al.Understanding extreme sea levels for broadscale coastal impact and adaptation analysis Nat Commun, 8 (2017), p. 16075

[27] BRAT development team. Broadview Radar Altimetry Toolbox software user manual (BRAT version 4.2.1). ESA; 2018.

[28] Nurse LA, McLean RF, Agard J, et al., Small islands, In: Barros VR, Field CB, Dokken DJ, (Eds.), Climate Change 2014: Impacts, Adaptation, and Vulnerability Part b: Regional Aspects Contribution of Working Group II to the Fifth Assessment Report of the Intergovernmental Panel on Climate Change, 2014, Cambridge University Press, Cambridge, United Kingdom and New York, NY, USA, 1613-1654.

[29] P. Wessel, W.H.F. SmithA global, self-consistent, hierarchical, high-resolution shoreline database J Geophys Res Solid Earth, 101 (1996), pp. 8741-8743

[30] VLIZ. IHO sea areas, version 2. 2017, (December 15, 2017): http://www.marineregions.org/.

[31] AVISO+. Ssalto/Duacs user handbook: Mozambique (M)SLA near-real time products. Ramonville St-Agne: CNES; 2016.

[32] AVISO+. Ssalto/Duacs experimental product handbook. Ramonville St-Agne: CNES; 2018.

[33] M. Sonnewald, C. Wunsch, P. HeimbachLinear predictability: a sea surface height case study J Clim, 31 (2018), pp. 2599-2611

[34] Addinsoft. XLSTAT statistical and data analysis solution, 2019, https://www.xlstat.com.

[35] A. Mémin, Y. Rogister, J. Hinderer, et al.Secular gravity variation at Svalbard (Norway) from ground observations and GRACE satellite data Geophys J Int, 184 (2011), pp. 11191130

[36] R. KwokArctic sea ice thickness, volume, and multiyear ice coverage: losses and coupled variability (1958-2018) Environ Res Lett, 13 (2018), p. 105005

[37] R.S. Nerem, D.P. Chambers, C. Choe, et al.Estimating mean sea level change from the TOPEX and Jason altimeter missions Mar Geod, 33 (2010), pp. 435-446

[38] M. Ablain, J.F. Legeais, P. Prandi, et al.Satellite altimetry-based sea level at global and regional scales Surv Geophys, 38 (2017), pp. 7-31

[39] I.R. Young, S. Zieger, A.V. BabaninGlobal trends in wind speed and wave height

Science, 332 (2011), pp. 451-455

[40] Y. Wada, J.T. Reager, B.F. Chao, et al.Recent changes in land water storage and its contribution to sea level variations Surv Geophys, 38 (2017), pp. 131-152

[41] M. Rodell, J.S. Famiglietti, D.N. Wiese, et al.Emerging trends in global freshwater availability Nature, 557 (2018), pp. 651-659

[42] V. Radić, R. HockGlaciers in the earth's hydrological cycle: assessments of glacier mass and runoff changes on global and regional scales Surv Geophys, 35 (2014), pp. 813-837

[43] P.S. Kench, M.R. Ford, S.D. OwenPatterns of island change and persistence offer alternate adaptation pathways for atoll nations Nat Commun, 9 (2018), p. 605

[44] H. Yang, M. Ma, J.R. Thompson, et al.Protect coastal wetlands in China to save endangered migratory birds Proc Natl Acad Sci USA, 114 (2017), pp. E5491-E5492 